Article

\title{
Isoprene Polymerization: Catalytic Performance of Iminopyridine Vanadium(III) Chloride versus Vanadium(III) Chloride
}

\author{
Mengmeng Zhao ${ }^{1, \dagger}{ }^{+}$Qaiser Mahmood ${ }^{1,+}$, Chuyang Jing ${ }^{1,2}$, Liang Wang ${ }^{1}$, Guangqian Zhu ${ }^{1,2}$, \\ Xianhui Zhang ${ }^{1,2}$ and Qinggang Wang ${ }^{1,2, *(D)}$ \\ 1 Key Laboratory of Biobased Materials, Qingdao Institute of Bioenergy and Bioprocess Technology, Chinese \\ Academy of Sciences, Qingdao 266000, China \\ 2 Center of Materials Science and Optoelectronics Engineering, University of Chinese Academy of Sciences, \\ Beijing 100049, China \\ * Correspondence: wangqg@qibebt.ac.cn; Tel.: +86-158-0658-1125 \\ + These authors contributed equally to this work.
}

Received: 25 April 2019; Accepted: 18 June 2019; Published: 2 July 2019

\begin{abstract}
A series of vanadium complexes bearing iminopyridine bidentate ligands with various electronic and steric properties: V1 $\left[\mathrm{CH}_{2} \mathrm{Ph}\right], \mathbf{V} 2\left[\mathrm{CMe}_{2} \mathrm{CH}_{2} \mathrm{CMe}_{3}\right], \mathbf{V} 3[\mathrm{Ph}]$ and $\mathbf{V 4}\left[2,6-{ }^{i} \mathrm{Pr}_{2} \mathrm{Ph}\right]$ were prepared and characterized by IR spectroscopy and microanalytical analysis. The catalytic capacity of all the complexes has been investigated for isoprene polymerization and was controlled by tuning the ligand structure with different $N$-alkyl and $N$-aryl groups. Activated by methylaluminoxane (MAO), the aryl-substituted complex V3 [Ph] exhibited high cis-1,4 selectivity (75\%), and the resultant polymers had high molecular weights $\left(M_{n}=6.6 \times 10^{4}\right)$ and narrow molecular weight distributions (PDI = 2.3). This catalyst showed high activity up to $734.4 \mathrm{~kg}$ polymer $(\mathrm{mol} \mathrm{V})^{-1} \mathrm{~h}^{-1}$ with excellent thermostability even stable at $70^{\circ} \mathrm{C}$. Compared to the traditional $\mathrm{VCl}_{3} / \mathrm{MAO}$ catalytic system, iminopyridine-supported V(III) catalysts displayed higher catalytic activities and changed the selectivity of monomer enchainment from trans- 1,4 to cis- 1,4 .
\end{abstract}

Keywords: polyisoprene; iminopyridine ligands; vanadium complexes; $\mathrm{VCl}_{3} / \mathrm{MAO}$; Ziegler-Natta polymerization

\section{Introduction}

Polydienes, a class of multipurpose elastomers which play a vital role in modern society, have attracted considerable attention of both industrial and academic communities. Advantages typical of both rubber and plastic materials make them superior over vulcanized rubber, therefore, these polymeric materials are widely employed as commodity material in tires, medical materials, sporting goods etc. [1-5]. Generally, polydienes are manufactured by the polymerization of conjugated dienes. Among various polydiene products, polyisoprenes are identified as important synthetic elastomer, due to their diversified microstructures $[1,2,3,4$, cis-1,4 and trans-1,4 stereoregularities in polymer] and thereby, a strong influence on the properties of the resulting polymer. For example, natural rubber mainly consists of cis-1,4 polyisoprene, and exhibits similar properties to the synthetic cis-1,4 regular polyisoprene, while trans-1,4 polyisoprene is nearly identical to the gutta-percha rubber or balata rubber [6,7].

Given the massive global demand of polyisoprene and limited supply of natural rubbers trigger many researchers to develop more reactive and controllable catalytic system either by changing the metal center of the catalysts or controlling the reaction conditions [8-10]. Regarding metal-based catalysts, the mainstream of catalysts relied on early transition metals ranging from group III to IV. For 
example, rare-earth metal and titanium catalysts afforded cis-1,4 or trans-1,4 polyisoprene with up to 98\% selectivity [11-15]. In addition, some late transition-metal catalysts were also studied for isoprene polymerization, such as well-defined Fe and Co complexes [16-23]. However, the polymerization of isoprene with mid-transition metal-based catalysts remains less explored. Vanadium-based catalysts, discovered in the 1950s, are used as the first homogeneous catalyst system for olefin polymerization [24]. After that, numerous vanadium-based catalysts for stereospecific polymerization of olefin have been intensively explored [25-28].

Specifically for isoprene polymerization, various vanadium metal-based catalytic systems have been studied. For instance, the combination of $\mathrm{VCl}_{3}, \mathrm{VCl}_{4}$, or $\mathrm{VOCl}_{3}$ with alkylaluminium, either in heterogeneous or homogeneous nature were extensively studied and yielded polyisoprene with high trans-1,4 structures [29-35]. However, the main disadvantage of these catalysts is that their active species can easily undergo deactivation, and, thus, affording low activities [36,37]. To address this issue, researchers focused to developing well-defined vanadium catalysts by introducing the ligand into the structure. To this end, numerous well-defined vanadium complexes have been investigated as catalysts for ethylene polymerization, however, few reports are available in which conjugated diene polymerization is explored [38-42]. In 2016s, the homogeneous catalytic system: Vanadium-[ONNO] complexes combined with $n$-butyl ethyl magnesium or triisobutyl aluminium, had been reported for isoprene polymerization. In this study, obtained polyisoprene was composed of $70 \% 3,4-$ and $30 \%$ 1,4-units [41]. Later in 2017s, Ricci et al. reported iminopyridine-vanadium complexes for isoprene polymerization showed good activities and produced cis-1,4 enriched polyisoprene [42].

It is noticed that iminopyridine ligands are widely studied for many catalytic reactions, due to their facile synthesis and easy to control the catalytic performance by means of different substituents [19-21,23]. To extend this study, herein, we reported the synthesis of a series of iminopyridine vanadium(III) complexes and employed as catalysts for isoprene polymerization. By means of different cocatalysts and reaction conditions, namely catalyst loadings, polymerization temperature and reaction time, the performance of title catalysts in term of activity and stereoselectivity of monomer enchainment were systematically investigated. Meanwhile, an in-depth isoprene polymerization was conducted using traditional Ziegler-Natta catalyst composed of $\mathrm{VCl}_{3}$ and methylaluminoxane (MAO), and compared the results with iminopyridine-vanadium catalyzed isoprene polymerization. The ligand modificationwith different substituents and reaction conditionat differet reaction temperatures, exhibited remarkable effects on the stereoselectivity of monomer enchainment.

\section{Materials and Methods}

\subsection{Materials}

All the manipulations of air/moisture sensitive compounds were carried out under argon atmosphere using standard Schlenk technique or in glove box. Toluene was refluxed over sodium for $6 \mathrm{~h}$, then distilled and stored over molecular sieves under nitrogen. Hexane and dichloromethane were refluxed over calcium hydride for $6 \mathrm{~h}$ and distilled and stored over molecular sieves under argon conditions. Isoprene was purchased from Aladdin Co. (Shanghai, China) and was purified by distillation over calcium hydride before use. $\mathrm{VCl}_{3}$ and $\mathrm{VCl}_{3}(\mathrm{THF})_{3}$ were purchased from Sigma-Aldrich Co. (Saint Louis, MO, USA). Methylaluminoxane (MAO, 1.5 M solution in toluene) was purchased from Aike Reagent $\mathrm{Co}$ (Chengdu, China). Triethylaluminum (AlEt ${ }_{3}, 1.0 \mathrm{M}$ solution in toluene) and triisobutylaluminum $\left(\mathrm{Al}(i-\mathrm{Bu})_{3}, 1.0 \mathrm{M}\right.$ solution in toluene) were purchased from Aladdin Co. (Shanghai, China). Other reagents were purchased from commercial sources and used without purification. 


\subsection{Synthesis of ligand $\mathbf{L} \mathbf{1}-\mathbf{L} 4$}

General procedure: A solution of the corresponding amine (1.0 equiv.) in dichloromethane was added to a solution of pyridine-2-carbaldehyde (1.0 equiv.) in dichloromethane containing $4 \AA$ molecular sieve $(300 \mathrm{mg})$. The mixture was stirred at room temperature. After overnight stirring, the reaction mixture was filtered, and the resulting solution was concentrated under reduced pressure to obtain the corresponding ligand [19].

1-Phenyl-N-(pyridin-2-ylmethylene)methanamine (L1): Yellow oil. Yield: $2.5 \mathrm{~g}(68 \%) .{ }^{1} \mathrm{H}$ NMR $(400$ $\left.\mathrm{MHz}, \mathrm{CDCl}_{3}, 298 \mathrm{~K}\right) \delta 8.64-8.63(\mathrm{~m}, 1 \mathrm{H}), 8.49(\mathrm{~s}, 1 \mathrm{H}), 8.06(\mathrm{~d}, J=7.6 \mathrm{~Hz}, 1 \mathrm{H}), 7.74-7.69(\mathrm{~m}, 1 \mathrm{H})$, 7.74-7.69 (m, 6H), 4.87 (s, 2H). ${ }^{13} \mathrm{C}$ NMR $\left(100 \mathrm{MHz}, \mathrm{CDCl}_{3}, 298 \mathrm{~K}\right) \delta$ 162.9, 154.6, 149.4, 138.7, 136.6, $128.6,128.2,127.2,124.8,121.4,65.0$.

2,4,4-Trimethyl- $N$-(pyridin-2-ylmethylene)pentan-2-amine (L2): Light yellow oil. Yield: $1.6 \mathrm{~g}(80 \%)$. ${ }^{1} \mathrm{H}$ NMR $\left(400 \mathrm{MHz}, \mathrm{CDCl}_{3}, 298 \mathrm{~K}\right) \delta 8.64-8.59(\mathrm{~m}, 1 \mathrm{H}), 8.34(\mathrm{~s}, 1 \mathrm{H}), 8.04-8.02(\mathrm{~m}, 1 \mathrm{H}), 7.74-7.70(\mathrm{~m}$, 1H), 7.30-7.27 (m, 1H), $1.71(\mathrm{~s}, 2 \mathrm{H}), 1.33(\mathrm{~s}, 6 \mathrm{H}), 0.95$ (s, 9H). ${ }^{13} \mathrm{C} \mathrm{NMR}\left(100 \mathrm{MHz}, \mathrm{CDCl}_{3}, 298 \mathrm{~K}\right) \delta 155.9$, $155.8,149.2,136.6,124.3,120.7,61.6,56.5,32.1,31.8,29.6$.

$\mathrm{N}$-(pyridin-2-ylmethylene)aniline (L3): Yellow oil. Yield: $1.3 \mathrm{~g}(78 \%) .{ }^{1} \mathrm{H} \mathrm{NMR}\left(400 \mathrm{MHz}, \mathrm{CDCl}_{3}\right.$, $298 \mathrm{~K}) \delta: 8.75-8.69(\mathrm{~m}, 1 \mathrm{H}), 8.61(\mathrm{~s}, 1 \mathrm{H}), 8.21(\mathrm{~d}, J=8.0 \mathrm{~Hz}, 1 \mathrm{H}), 7.84-7.80(\mathrm{~m}, 1 \mathrm{H}), 7.46-7.35(\mathrm{~m}, 3 \mathrm{H})$, 7.31-7.27 (m, 3H). ${ }^{13} \mathrm{C}$ NMR (100 MHz, CDCl $\left.3,298 \mathrm{~K}\right) \delta 160.6,154.5,150.9,149.6,136.7,129.2,126.7$, $125.1,121.9,121.1$.

2,6-Diisopropyl- $N$-(pyridin-2-ylmethylene)aniline (L4): Light yellow oil. Yield: $1.2 \mathrm{~g}(32 \%) .{ }^{1} \mathrm{H} \mathrm{NMR}$ $\left(400 \mathrm{MHz}, \mathrm{CDCl}_{3}, 298 \mathrm{~K}\right) \delta 8.75-8.73(\mathrm{~m}, 1 \mathrm{H}), 8.32(\mathrm{~s}, 1 \mathrm{H}), 8.29-8.26(\mathrm{~m}, 1 \mathrm{H}), 7.88-7.82(\mathrm{~m}, 1 \mathrm{H}), 7.43-7.40$ (m, 1H), 7.20-7.10 (m, 3H), 3.03-2.92 (m, 2H), $1.18(\mathrm{~d}, J=7.2 \mathrm{~Hz}, 12 \mathrm{H}) .{ }^{13} \mathrm{C}$ NMR $\left(100 \mathrm{MHz}, \mathrm{CDCl}_{3}, 298\right.$ K) $\delta 163.1,154.5,149.8,148.5,137.4,136.9,125.5,124.1,123.2,121.5,28.1,23.6$.

\subsection{Synthesis of Vanadium Complexes V1-V4}

All complexes were prepared under nitrogen atmosphere. The equimolar solution of $\mathrm{VCl}_{3}(\mathrm{THF})_{3}$ and corresponding ligands in anhydrous dichloromethane $(10 \mathrm{~mL})$ was stirred for $24 \mathrm{~h}$ at room temperature. Dark solids were filtered off from the solution. The filtrate was concentrated to $2 \mathrm{~mL}$, layered with $5 \mathrm{~mL}$ hexane and was then cooled to $0{ }^{\circ} \mathrm{C}$ for $4 \mathrm{~h}$. The precipitates were filtered and washed with hexane, dried under vacuum to give the vanadium complexes [39].

(Benzyl Iminopyridine) $\mathrm{VCl}_{3}$ (V1): A mixture of $\mathbf{L 1}(105.1 \mathrm{mg}, 0.54 \mathrm{mmol})$ and anhydrous $\mathrm{VCl}_{3}(\mathrm{THF})_{3}$ ( $0.2 \mathrm{~g}, 0.54 \mathrm{mmol})$ was stirred to give $\mathbf{V} 1$ as yellow solid $(152.0 \mathrm{mg}, 67 \%)$. ATR-IR $\left(\mathrm{cm}^{-1}\right): 3059,1599$ $v(\mathrm{C}=\mathrm{N}), 1454,1305,1053,1026,986,758,703$. Anal. Calcd. For $\mathrm{C}_{13} \mathrm{H}_{12} \mathrm{Cl}_{3} \mathrm{~N}_{2} \mathrm{~V} \cdot 1 / 2\left(\mathrm{CH}_{2} \mathrm{Cl}_{2}\right): \mathrm{C}, 40.94$; $\mathrm{H}, 3.31$; N, 7.07; found: $\mathrm{C}, 40.59 ; \mathrm{H}, 4.62 ; \mathrm{N}, 7.13$.

(Octyl Iminopyridine) $\mathrm{VCl}_{3}$ (V2): A mixture of $\mathbf{L} 2(116.8 \mathrm{mg}, 0.54 \mathrm{mmol})$ and anhydrous $\mathrm{VCl}_{3}(\mathrm{THF})_{3}$ $(0.2 \mathrm{~g}, 0.54 \mathrm{mmol})$ was stirred to give V2 as yellow solid $(70.0 \mathrm{mg}, 29 \%)$. ATR-IR $\left(\mathrm{cm}^{-1}\right): 3093,1609$ $v(\mathrm{C}=\mathrm{N}), 1483,1032,985$, 773. Anal. Calcd. For $\mathrm{C}_{14} \mathrm{H}_{22} \mathrm{Cl}_{3} \mathrm{~N}_{2} \mathrm{~V}: \mathrm{C}, 44.76 ; \mathrm{H}, 5.90 ; \mathrm{N}, 7.46$; found: $\mathrm{C}$, 45.38; H, 5.99; N, 7.32.

(Phenyl Iminopyridine) $\mathrm{VCl}_{3}(\mathbf{V} 3)$ : A mixture of $\mathbf{L 3}(97.5 \mathrm{mg}, 0.54 \mathrm{mmol})$ and anhydrous $\mathrm{VCl}_{3}(\mathrm{THF})_{3}$ $(0.2 \mathrm{~g}, 0.54 \mathrm{mmol})$ was stirred to give $\mathbf{V 3}$ as pink solid $(130.0 \mathrm{mg}, 59 \%)$. ATR-IR $\left(\mathrm{cm}^{-1}\right): 2959,1592$ $v(\mathrm{C}=\mathrm{N}), 1458,1308,1024,774$, 765. Anal. Calcd. For $\mathrm{C}_{12} \mathrm{H}_{10} \mathrm{Cl}_{3} \mathrm{~N}_{2} \mathrm{~V} \cdot \mathrm{C}_{4} \mathrm{H}_{8} \mathrm{O}: \mathrm{C}, 46.69 ; \mathrm{H}, 4.41 ; \mathrm{N}, 6.81$; found: $\mathrm{C}, 46.61 ; \mathrm{H}, 3.91 ; \mathrm{N}, 7.51$.

(2,6-Diisopropylphenyl Iminopyridine) $\mathrm{VCl}_{3}$ (V4): A mixture of $\mathbf{L} 4(142.6 \mathrm{mg}, 0.54 \mathrm{mmol}$ ) and anhydrous $\mathrm{VCl}_{3}(\mathrm{THF})_{3}(0.2 \mathrm{~g}, 0.54 \mathrm{mmol})$ was stirred to give $\mathrm{V} 4$ as pink solid $(115.0 \mathrm{mg}, 63 \%)$. ATR-IR $\left(\mathrm{cm}^{-1}\right)$ : 3330, $1596 v(\mathrm{C}=\mathrm{N}), 1487,1025,777$, 765. Anal. Calcd. For $\mathrm{C}_{18} \mathrm{H}_{22} \mathrm{Cl}_{3} \mathrm{~N}_{2} \mathrm{~V}: \mathrm{C}, 51.03 ; \mathrm{H}, 5.23 ; \mathrm{N}, 6.61$; found: $\mathrm{C}, 49.84 ; \mathrm{H}, 5.16 ; \mathrm{N}, 6.43$. 


\subsection{Polymerization Procedure}

The polymerization of isoprene in toluene was carried out in a $25 \mathrm{~mL}$ Schlenk reactor. In a typical process, the reactor was heated, dried in vacuum, and recharged with argon for more than three times. The vanadium complex was weighed in a glove box and then introduced into a Schlenk reactor. The reactor was taken out of the glove box. The required amount of solvent, isoprene and aluminum cocatalyst was added in sequence into the reactor under nitrogen via a septum. After the required reaction time, the flask was opened to air, and the polymerization was quenched with a diluted $\mathrm{HCl}$ solution of methanol (methanol/ $\mathrm{HCl}=50 / 1$ ). The resulting solution was poured into a large volume of methanol containing 2,6-bis(1,1-dimethylethyl)-4-methylphenol (BHT) as the stabilizing agent. The polymer was collected by filtration and washed with ethanol several times and dried at room temperature under vacuum. The polymer yields were determined by gravimetry.

\subsection{Polymer Characterization}

The number-average and weight-average molecular weights $\left(M_{n}\right.$ and $\left.M_{\mathrm{w}}\right)$ and molecular weight distributions $\left(M_{\mathrm{W}} / M_{n}\right)$ of polymers were measured by gel permeation chromatography (GPC) using a PL-GPC 220 chromatography. Plgel MIXED-B LS $300 \mathrm{~mm} \times 7.5 \mathrm{~mm}$ column was employed and maintained at $150{ }^{\circ} \mathrm{C}$. Trichlorobenzene stabilized with $0.0125 \%$ BHT used as eluent at a flow rate of $1.0 \mathrm{~mL} / \mathrm{min}$. The molecular weights of polyisoprene were determined by using a polystyrene calibration. The injection volume of the sample solution was $200 \mu \mathrm{L}$. The microstructure of polyisoprene was determined by NMR spectra on a Bruker Advance 400 spectrometer at $298 \mathrm{~K}$. ${ }^{1} \mathrm{H}$ NMR, and ${ }^{13} \mathrm{C}$ NMR spectra of ligands and polyisoprene were recorded in $\mathrm{CDCl}_{3}$. The polyisoprene microstructure of the 1,4 and 3,4 ratio was determined from ${ }^{1} \mathrm{H}$ NMR of the $1,4=\mathrm{CH}$ signals at $5.15 \mathrm{ppm}$ and the $3,4=\mathrm{CH}_{2}$ signal at $4.7 \mathrm{ppm}$. The trans/cis-1,4 stereoisomer ratio was determined from ${ }^{13} \mathrm{C}$ NMR of the $-\mathrm{CH}_{3}$ signals of cis-1,4 at $23.8 \mathrm{ppm}$ and trans $-1,4$ at $16.3 \mathrm{ppm}$.

\section{Results}

\subsection{Synthesis and Characterization of Iminopyridine Vanadium(III) Complexes}

The general synthetic method of new vanadium complexes used in this study is shown in Scheme 1. The iminopyridine ligands (L1-L4) were synthesized by following the reported procedure, and their structures were identified by ${ }^{1} \mathrm{H}$ and ${ }^{13} \mathrm{C}$ NMR. The reaction of $\mathrm{VCl}_{3}(\mathrm{THF})_{3}$, with 1.0 equivalent of corresponding iminopyridine ligand (L1-L4) in $\mathrm{CH}_{2} \mathrm{Cl}_{2}$ solution, afforded a set of four vanadium complexes in moderate yields (V1, 67\%; V2, 29\%; V3, 59\%; V4, 63\%). All these complexes were characterized by ATR-IR and elemental analysis. However, our multiple attempts to obtain the suitable single crystals for $\mathrm{X}$-ray diffraction and high resolution mass spectrum analyses of all these complexes were failed, due to their relatively high instability in air and moisture. Indeed, crystals were also not obtained in a glove box. Because of the paramagnetic nature of these vanadium complexes, the NMR also did not give clear information.

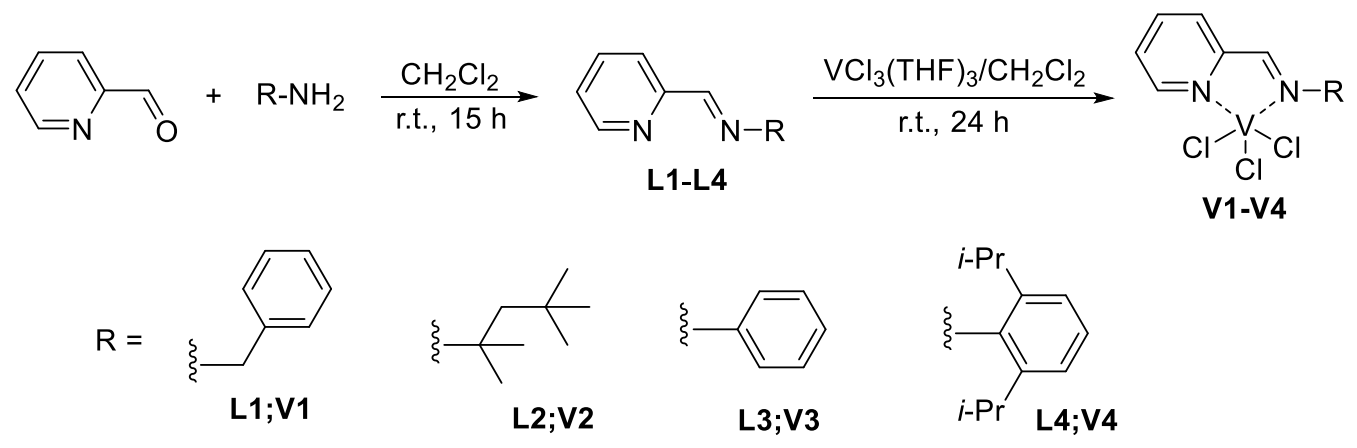

Scheme 1. Synthesis of iminopyridine ligands and their V(III) complexes. 


\subsection{Isoprene Polymerization Studies Catalyzed by $\mathrm{VCl}_{3} / \mathrm{MAO}$}

Initially, traditional Ziegler-Natta catalyst, i.e., $\mathrm{VCl}_{3} /$ alkyl aluminum, was employed to optimize the reaction conditions for the polymerization of isoprene. For this, initially, the effects of different cocatalysts and reaction solvents were examined, and the obtained results are presented in Table S1 (Supplementary Materials). Specifically, three cocatalysts, namely methylaluminoxane (MAO), triehtylaluminium $\left(\mathrm{AlEt}_{3}\right)$, and triisobutylaluminium $\mathrm{Al}(i-\mathrm{Bu})_{3}$, were evaluated. At $50{ }^{\circ} \mathrm{C}, \mathrm{VCl}_{3}$ in combination with MAO displayed the highest activity for a run time of $15 \mathrm{~h}$ and the resultant polymer possessed high molecular weight $\left(M_{n}=1.2 \times 10^{5} \mathrm{~g} / \mathrm{mol}\right)$, however, relatively broad molecular weight distributions $\left(M_{\mathrm{w}} / M_{n}=2.3\right)$ was identified as compared to the polymer obtained in the presence of $\mathrm{AlEt}_{3}\left(M_{\mathrm{W}} / M_{n}=1.8\right)$ cocatalyst (Table S1, entries 1 and 2). Regarding the microstructural properties, compared to the polyisoprene obtained with $\mathrm{AlEt}_{3}\left(98 \%\right.$ of trans $-1,4$ units) and $\mathrm{Al}(i-\mathrm{Bu})_{3}$ ( $>99 \%$ of trans $-1,4$ units) cocatalysts, slightly poor selectivities were identified for the $\mathrm{VCl}_{3} / \mathrm{MAO}$ induced polyisoprene: Eighty-three percent trans-1,4 units. Taking the activity, $M_{n}$ and $M_{\mathrm{w}} / M_{n}$ into consideration, $\mathrm{MAO}$ was chosen as the optimal cocatalyst for further isoprene polymerization tests. Polymerization tests were performed in polar and non-polar solvents, such as hexane, toluene and dichloromethane, to study the effect of the reaction medium. Polymerization in toluene gave relatively higher yields with comparatively high stereoselectivities of polymer than the polymerization performed in hexane. (Table S1, entry 5, Supplementary Materials). However, some white powder with good solubility in $\mathrm{CDCl}_{3}$ was collected when polymerization performed in dichloromethane. The ${ }^{1} \mathrm{H}$ and ${ }^{13} \mathrm{C}$ NMR spectra of this white powder showed no characteristic signal of polyisoprene which indicated no polymer was formed at all in dichloromethane (Table S1, entry 4, Supplementary Materials). Therefore, toluene was found as the best reaction medium and used for further examinations.

To further explore the catalytic scope of $\mathrm{VCl}_{3} / \mathrm{MAO}$ system, three more reaction parameters, namely reaction temperature, time, and the amount of cocatalyst, were tested-the results are given in Table 1. Initially, the thermo-stability of active species was examined at different reaction temperatures (e.g., 25,50 and $70^{\circ} \mathrm{C}$ ) with $[\mathrm{V}] /[\mathrm{IP}] /[\mathrm{Al}]$ ratio fixed at 1/200/30 (Table 1, entries 1-3). The highest yield of $88 \%$ was found at $25^{\circ} \mathrm{C}$, which slightly improved to $90 \%$ at $50{ }^{\circ} \mathrm{C}$; however, this yield dramatically fell to $65 \%$ at $70{ }^{\circ} \mathrm{C}$ for the run time of $36 \mathrm{~h}$. This lower yield at elevated temperature would be due to the partial deactivation of active species [43]. Meanwhile, regioselectivity of monomer enchainment was decreased on increasing the reaction temperature: Polymer obtained at $25{ }^{\circ} \mathrm{C}$ possessed the highest amount of trans $-1,4$ regularities $(>99 \%)$. By considering the high regioselectivity at a lower temperature, a reaction temperature of $25^{\circ} \mathrm{C}$ was used to examine the lifetime of active species. For this, polymerization tests were performed for different run times, namely $5,15,24,36$, and $48 \mathrm{~h}$-the results are given in Figure 1. The results revealed that isoprene yields were consistently increased on prolonging the reaction time and the highest yield of $97 \%$ was found for a run time of $48 \mathrm{~h}$ (Table 1 , entry 7). This continuous growth in the yield proved that active species had long life-times and showed high stability even after $48 \mathrm{~h}$. Furthermore, variation in reaction time showed no effect on the regioselectivities of the resultant polymer and in all polymer samples possessed more than $99 \%$ trans $-1,4$ units. However, the results of molecular weights and molecular weights distribution showed no clear trend. The polymerization tests were performed at different $[\mathrm{Al}] /[\mathrm{V}]$ ratio (Table 1, entries $8-10$ ) using fixed a temperature of $25^{\circ} \mathrm{C}$. On decreasing [Al]/[V] ratio from 30 to 10 led to a quantitative yield $(>99 \%)$. However, a further decrease in cocatalysts loading gave lower yields (Table 1, entries 9 and 10). Interestingly, we found that even 1:1 equivalent of $\mathrm{VCl}_{3}$ and $\mathrm{MAO}$ could initiate the polymerization of isoprene (Table 1, entry 10). The relationship of the regioselectivity of isoprene polymerization with the change in $[\mathrm{Al}] /[\mathrm{V}]$ ratio is trivial, and all reaction gave trans-1,4 polyisoprene with $>99 \%$ selectivity. Whereas, lower $M_{n}$ and slightly broad $M_{\mathrm{w}} / M_{n}$ were observed when decreasing the [Al]/[V] ratio from 30 to 10 . However, the opposite trend of $M_{n}$ and $M_{\mathrm{w}} / M_{n}$ were obtained on changing the $\mathrm{Al} / \mathrm{V}$ ratio from 10 to 1 (Table 1, entries 9 and 10). 
Table 1. Effects of temperature and time of $\mathrm{VCl}_{3} /$ methylaluminoxane (MAO) catalyst ${ }^{\mathrm{a}}$.

\begin{tabular}{|c|c|c|c|c|c|c|c|c|c|}
\hline \multirow{2}{*}{ Entry } & \multirow{2}{*}[\mathrm{V}]{$/[\mathrm{IP}] /[\mathrm{MAO}]$} & \multirow{2}{*}{$\begin{array}{l}\text { Time } \\
\text { (h) }\end{array}$} & \multirow{2}{*}{$\begin{array}{c}\text { Temp } \\
\left({ }^{\circ} \mathrm{C}\right)\end{array}$} & \multirow{2}{*}{$\begin{array}{l}\text { Yield } \\
(\%)^{b}\end{array}$} & \multirow{2}{*}{$\begin{array}{c}M_{n}{ }^{c} \\
\left(\times 10^{-4}\right)\end{array}$} & \multirow{2}{*}{$\mathbf{M}_{\mathrm{w}} / \mathbf{M}_{\mathbf{n}}{ }^{\mathrm{c}}$} & \multicolumn{3}{|c|}{ Microstructure(\%) } \\
\hline & & & & & & & trans $-1,4$ & cis- 1,4 & 3,4 \\
\hline 1 & $1 / 200 / 30$ & 36 & 50 & 90 & 5.1 & 2.3 & 83 & 14 & 3 \\
\hline 2 & $1 / 200 / 30$ & 36 & 70 & 65 & 0.5 & 2.9 & 68 & 25 & 7 \\
\hline 3 & $1 / 200 / 30$ & 36 & 25 & 88 & 7.3 & 1.8 & $>99$ & 0 & 0 \\
\hline 4 & $1 / 200 / 30$ & 5 & 25 & 6 & 8.0 & 1.9 & $>99$ & 0 & 0 \\
\hline 5 & $1 / 200 / 30$ & 15 & 25 & 28 & 19.3 & 2.0 & $>99$ & 0 & 0 \\
\hline 6 & $1 / 200 / 30$ & 24 & 25 & 65 & 3.1 & 3.5 & $>99$ & 0 & 0 \\
\hline 7 & $1 / 200 / 30$ & 48 & 25 & 97 & 3.5 & 2.4 & $>99$ & 0 & 0 \\
\hline 8 & $1 / 200 / 10$ & 48 & 25 & $>99$ & 1.2 & 3.5 & $>99$ & 0 & 0 \\
\hline 9 & $1 / 200 / 5$ & 48 & 25 & 18 & 2.4 & 2.0 & $>99$ & 0 & 0 \\
\hline 10 & $1 / 200 / 1$ & 48 & 25 & 13 & 5.7 & 1.9 & $>99$ & 0 & 0 \\
\hline
\end{tabular}

${ }^{\mathrm{a}}$ General condition: $[\mathrm{Ip}]_{0}=5.0 \mathrm{M}, \mathrm{V}_{\text {tol. }}=2 \mathrm{~mL} .{ }^{\mathrm{b}}$ Determined by isolated yield. ${ }^{\mathrm{c}}$ Determined by gel permeation chromatography (GPC). ${ }^{\mathrm{d}}$ Determined by ${ }^{1} \mathrm{H}$ NMR and ${ }^{13} \mathrm{C}$ NMR.

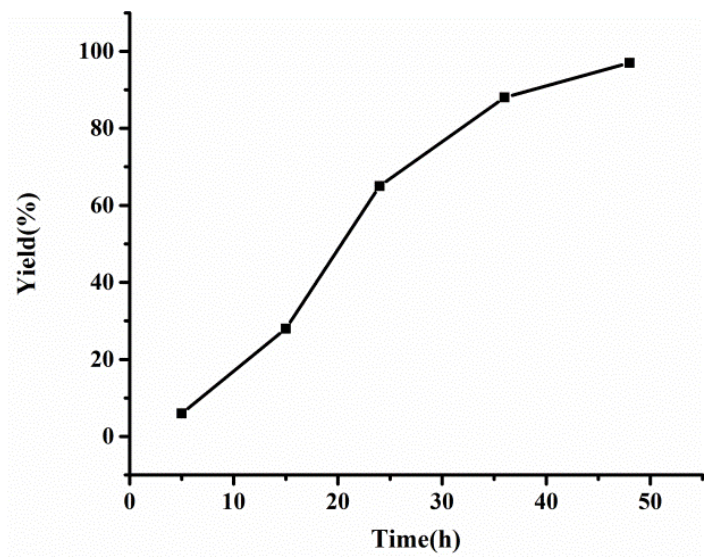

Figure 1. Plot of reaction time vs. yield of the polyisoprene obtained in Table 1, entries 3-7.

\subsection{Isoprene Polymerization Catalyzed by V1-V4 Complexes}

In order to investigate the catalytic capacity of iminopyridine vanadium complexes V1-V4 for isoprene polymerization, $\mathrm{MAO}$ was employed as cocatalyst. Typical polymerization tests were performed in toluene at $50^{\circ} \mathrm{C}$ and results are summarized in Table 2. All the four vanadium complexes showed higher catalytic activities than the activities observed for the $\mathrm{VCl}_{3} / \mathrm{MAO}$ catalytic system for a run time of $5 \mathrm{~h}$. These results are highlighting the key role of ligand in enhancing the stability of active species, which thereby improve the catalytic activities. The catalytic performances of these catalysts were significantly influenced by the different $\mathrm{N}$-alkyl/aryl-substituents of the iminopyridine ligands. For instance, catalysts $\mathbf{V} \mathbf{1}\left[\mathrm{CH}_{2} \mathrm{Ph}\right]$ and $\mathbf{V} 2\left[\mathrm{Cme}_{2} \mathrm{CH}_{2} \mathrm{Cme}_{3}\right]$ bearing $\mathrm{N}$-alkyl substituents displayed relatively lower activities than catalysts $\mathbf{V} 3[\mathrm{Ph}]$ and $\mathbf{V} 4\left[2,6{ }^{i}{ }^{i} \mathrm{Pr}_{2} \mathrm{Ph}\right]$ containing $\mathrm{N}$-aryl-substituents (Table 2, entries 1, 2 vs. entries 3, 4). V1 $\left[\mathrm{CH}_{2} \mathrm{Ph}\right]$ and $\mathbf{V} \mathbf{2}\left[\mathrm{Cme}_{2} \mathrm{CH}_{2} \mathrm{Cme}_{3}\right]$ resulted $29 \%$ and $26 \%$ yields of polyisoprene respectively (Table 2, entries 1 and 2). These yields of polymer are significantly lower than the $94 \%$ and $90 \%$ obtained for the $\mathbf{V} 3[\mathrm{Ph}]$, and $\mathbf{V} 4\left[2,6{ }^{i}{ }^{i} \mathrm{Pr}_{2} \mathrm{Ph}\right]$ catalyzed isoprene polymerization respectively (Table 2, entries 1 and 2 verses 3 and 4). This difference in catalytic performance would be due to the different electronic nature of the ligand support. The $\mathrm{N}$-aryl groups of complexes $\mathrm{V} 3[\mathrm{Ph}]$ and $\mathbf{V} 4\left[2,6-{ }^{i} \mathrm{Pr}_{2} \mathrm{Ph}\right]$ relatively increases the Lewis character of the active species and thereby enhances the monomer insertion. Thus, high conversions were observed for catalysts $\mathbf{V} 3$ [Ph] and $\mathbf{V} 4$ [2,6- $\left.{ }^{i} \mathrm{Pr}_{2} \mathrm{Ph}\right]$. Meanwhile, complex V4 [2,6- $\left.{ }^{i} \mathrm{Pr}_{2} \mathrm{Ph}\right]$ was less active catalyst than the $\mathrm{N}$-phenyl substituted $\mathbf{V} 3$, it would be due to the more steric hindrance induced by two isopropyl substituents around the active species of V4. Regarding the properties of the polymer, the complex V3 [Ph] bearing the $N$-phenyl group afforded high molecular weights polyisoprene $\left(M_{n}=8.2 \times 10^{4}\right)$ with narrow polydispersity 
(Table 2, entry 3). The GPC results of the obtained polymers displayed unimodal curves, which indicated single-site active species (Figure 2).

Table 2. Effects of catalyst and cocatalyst by iminopyridine vanadium complexes ${ }^{\mathrm{a}}$.

\begin{tabular}{|c|c|c|c|c|c|c|c|c|c|}
\hline \multirow{2}{*}{ Entry } & \multirow{2}{*}{ Cat. } & \multirow{2}{*}{ Cocat. } & \multirow{2}{*}{$\begin{array}{l}\text { Time } \\
\text { (h) }\end{array}$} & \multirow{2}{*}{$\begin{array}{l}\text { Yield } \\
(\%)^{b}\end{array}$} & \multirow{2}{*}{$\begin{array}{c}M_{n}{ }^{c} \\
\left(\times 10^{-4}\right)\end{array}$} & \multirow{2}{*}{$\underset{\mathrm{c}}{\mathbf{M}_{\mathbf{w}} / \mathbf{M}_{\mathbf{n}}}$} & \multicolumn{3}{|c|}{ Microstructure $(\%)^{d}$} \\
\hline & & & & & & & trans $-1,4$ & cis- 1,4 & 3,4 \\
\hline 1 & V1 & MAO & 5 & 29 & 3.4 & 3.7 & 22 & 54 & 24 \\
\hline 2 & V2 & MAO & 5 & 26 & 2.3 & 1.7 & 36 & 47 & 17 \\
\hline 3 & V3 & MAO & 1 & 94 & 8.2 & 2.2 & 0 & 75 & 25 \\
\hline 4 & V4 & MAO & 5 & 92 & 3.6 & 2.2 & 9 & 67 & 24 \\
\hline 5 & V3 & $\mathrm{AlEt}_{3}$ & 16 & 0 & - & - & - & - & - \\
\hline 6 & V3 & $\mathrm{Al}(\mathrm{i}-\mathrm{Bu})_{3}$ & 16 & 0 & - & - & - & - & - \\
\hline
\end{tabular}

${ }^{\text {a }}$ Polymerization in toluene $(5 \mathrm{~mL})$ at $50{ }^{\circ} \mathrm{C},[\mathrm{Ip}]=4.0 \mathrm{~mol} / \mathrm{L},[\mathrm{V}] /[\mathrm{Ip}] /\left[\right.$ cocat.] $=1 / 2000 / 100 .{ }^{\mathrm{b}}$ Determined by isolated yield. ${ }^{c}$ Determined by gel permeation chromatography (GPC). ${ }^{d}$ Determined by ${ }^{1} \mathrm{H}$ NMR and ${ }^{13} \mathrm{C}$ NMR.

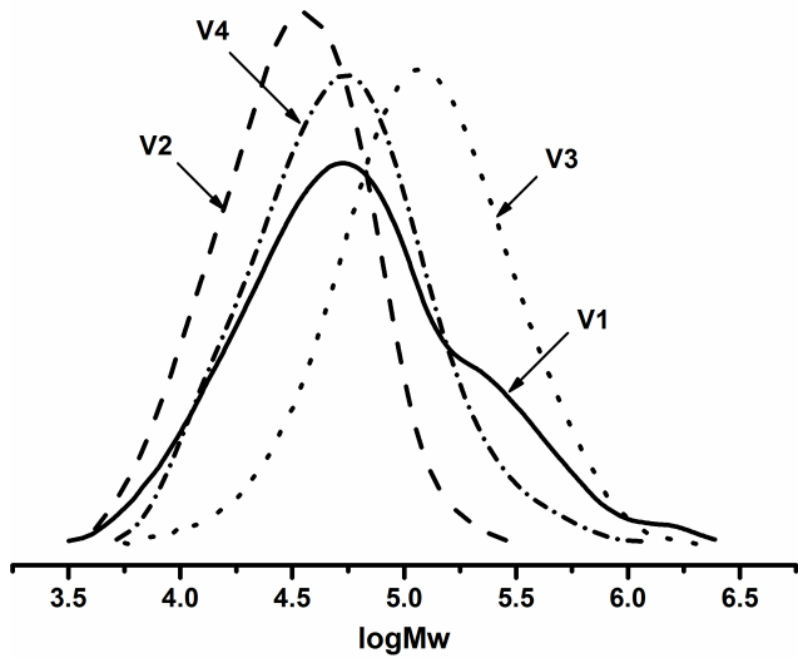

Figure 2. GPC curves of polyisoprene obtained using V1-V4/MAO catalyst system (Table 2, entry 1-4).

The different $\mathrm{N}$-alkyl or $\mathrm{N}$-aryl also had significant effects on the regioselectivity of isoprene polymerization. Complexes V1, V2 and V4 all showed low selectivities as resultant polymer possessed a mixture of trans-1,4, cis-1,4 and 3,4 units. However, complex V3 gave a high selectivity for cis-1,4 units and generated a polymer which was composed of cis-1,4/3,4 regularities with a ratio of 3:1 without trans $-1,4$ units. Meanwhile, it was found that other cocatalysts, such as $\mathrm{AlEt}_{3}$ and $\mathrm{Al}(i-\mathrm{Bu})_{3}$ combined with V3, were not able to catalyze the polymerization of isoprene under the same reaction conditions (Table 2, entries 5 and 6). The ${ }^{13} \mathrm{C} \mathrm{NMR}$ spectra of the polyisoprene obtained with $\mathrm{VCl}_{3} / \mathrm{MAO}$ (Table 1, entry 3) and V3/MAO (Table 2, entry 3) are displayed in Figure 3. It is observed that $\mathrm{VCl}_{3} / \mathrm{MAO}$ gave a polymer having $100 \%$ trans-1,4 units and V3/MAO produced polyisoprene showed high cis-1,4 (75\%) content without the appearance of trans-1,4 units. 
$\mathrm{CH}_{3}-($ trans-1,4)

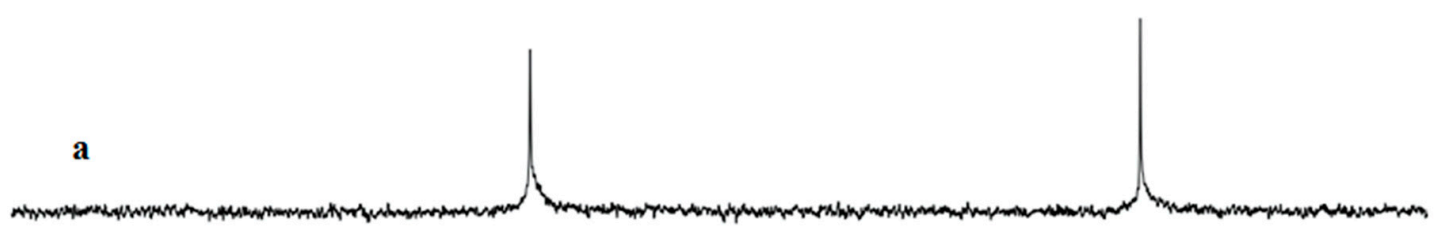

$\mathrm{CH}_{3}-(\mathrm{cis}-\mathbf{1 , 4 )}$

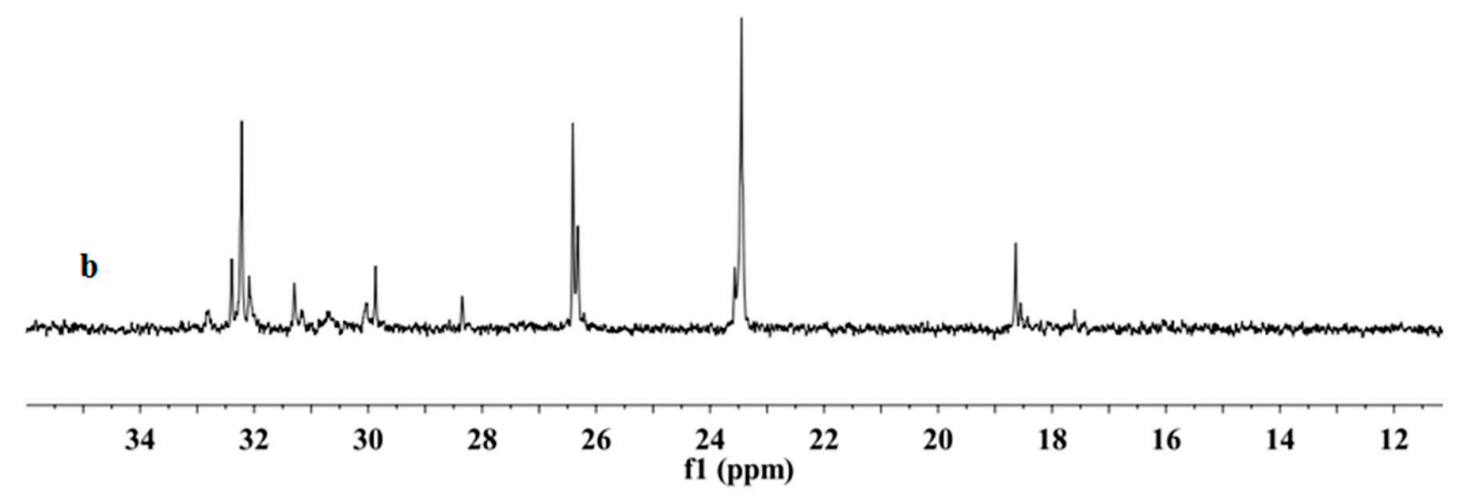

Figure $3 .{ }^{13} \mathrm{C}$ NMR spectra of polyisoprene obtained by $\mathrm{VCl}_{3} / \mathrm{MAO}$ (a: Table 1, entry 3 ) and V3/MAO (b: Table 2, entry 3).

The aim of this study was to investigate the effect of $\mathrm{Al} / \mathrm{V}$ ratio and temperature on the isoprene polymerization. Therefore, the complex V3 was used as model catalysts, and the obtained results are displayed in Table 3 . With temperature fixed at $50{ }^{\circ} \mathrm{C}, \mathrm{Al} / \mathrm{V}$ ratios varied systematically from 100 to 10 (Table 2, entry 3, Table 3, entry 1, 2). At Al/V ratio of 50 or 10, lower yields of polymer were observed. The molecular weight of the polyethylene ranging from 8.2 to $5.4 \times 10^{4}$ and exhibited moderate polydispersity $\left(M_{\mathrm{W}} / M_{\mathrm{n}}=2.2 \sim 1.9\right)$, which indicated a single-site active species. Likewise, as the ratio of $\mathrm{Al} / \mathrm{V}$ decreased, the cis-1,4 content of polyisoprene consistently decreased, and trans-1,4 units were started to appear in the resultant polymer which would be due to the different active center (Table 3, entries 1 and 2). Meanwhile, the influence of temperature on the V 3 catalyzed polymerization of isoprene was also studied (Figure 4). It was found that catalytic activities slightly decreased on elevating the reaction temperature. When polymerization was performed at $70{ }^{\circ} \mathrm{C}$, activity slightly reduced to $91 \%$, which indicated the high thermal stability of active species induced by V3/MAO catalytic system (Table 3, entry 3). Further lowering the reaction temperature from 50 to $25^{\circ} \mathrm{C}$ afforded slightly lower polymer yield of $86 \%$ (Table 3, entry 4 ). By contrast, number average molecular weights were improved on decreasing the reaction temperature to $25^{\circ} \mathrm{C}$. It can be ascribed to the lower chain transfer reaction as compared to the chain propagation on lowering the reaction temperature. The reaction performed at $0{ }^{\circ} \mathrm{C}$ resulted in a substantial decrease in polymer yield (Table 3, entry 5). It may be due to the generation of less number of active species at a temperature lower than $0{ }^{\circ} \mathrm{C}$. When the polymerization was conducted at $0{ }^{\circ} \mathrm{C}$, the trans-1,4 selectivity of the generated polymer dramatically increased from $0 \%$ to $85 \%$ even with very low polymer yield (Table 3, entry 5). In the 10 min reaction time with $\mathbf{V} 3$ catalyzed isoprene polymerization, $90 \%$ yield of polyisoprene with high activity up to $734.4 \mathrm{~kg}$ polymer $(\mathrm{mol} \mathrm{V})^{-1} \mathrm{~h}^{-1}$ was achieved (Table 3, entry 6). Prolongation of the reaction time to 2 $\mathrm{h}$ resulted in full conversion, and obtained polymer showed relatively high $M_{n}$ value. The polymer obtained in $10 \mathrm{~min}$ or $2 \mathrm{~h}$, showed similar stereoselectivity as $75 \%$ of cis-1,4 and $25 \%$ of 3,4 units. 
Table 3. Effects of temperature and amount of cocatalyst by complex V3 ${ }^{\mathrm{a}}$.

\begin{tabular}{|c|c|c|c|c|c|c|c|c|c|}
\hline \multirow{2}{*}{ Entry } & \multirow{2}{*}{ Temp. } & \multirow{2}{*}{ Time } & \multirow{2}{*}{$\begin{array}{l}\text { Yield } \\
(\%)^{b}\end{array}$} & \multirow{2}{*}{$\underset{\left(\times 10^{-4}\right)}{M_{n}{ }^{c}}$} & \multirow{2}{*}{$\mathbf{M}_{\mathrm{w}} / \mathbf{M}_{\mathrm{n}}^{\mathrm{c}}$} & \multirow{2}{*}{$\underset{\mathrm{d}}{\text { Activity }}$} & \multicolumn{3}{|c|}{ Microstructure( $\%)^{e}$} \\
\hline & & & & & & & trans $-1,4$ & cis- 1,4 & 3,4 \\
\hline $1^{\mathrm{f}}$ & $50{ }^{\circ} \mathrm{C}$ & $1 \mathrm{~h}$ & 76 & 5.4 & 2.1 & 103.4 & 2 & 73 & 25 \\
\hline $2 \mathrm{~g}$ & $50{ }^{\circ} \mathrm{C}$ & $1 \mathrm{~h}$ & 10 & 7.8 & 1.9 & 13.6 & 14 & 65 & 21 \\
\hline 3 & $70{ }^{\circ} \mathrm{C}$ & $1 \mathrm{~h}$ & 91 & 6.6 & 2.0 & 123.8 & 0 & 75 & 25 \\
\hline 4 & $25^{\circ} \mathrm{C}$ & $1 \mathrm{~h}$ & 86 & 11.3 & 2.0 & 117.0 & 0 & 75 & 25 \\
\hline 5 & $0{ }^{\circ} \mathrm{C}$ & $1 \mathrm{~h}$ & 5 & 0.2 & 3.6 & 6.8 & 85 & 7 & 8 \\
\hline 6 & $50{ }^{\circ} \mathrm{C}$ & $10 \min$ & 90 & 6.6 & 2.3 & 734.4 & 0 & 75 & 25 \\
\hline 7 & $50^{\circ} \mathrm{C}$ & $2 \mathrm{~h}$ & $>99$ & 23.9 & 2.9 & 68.0 & 0 & 75 & 25 \\
\hline
\end{tabular}

${ }^{a}$ Polymerization in toluene $(5 \mathrm{~mL}),[\mathrm{Ip}]=4.0 \mathrm{~mol} / \mathrm{L},[\mathrm{V} 3] /[\mathrm{Ip}] /[\mathrm{MAO}]=1 / 2000 / 100 .{ }^{\mathrm{b}}$ Determined by isolated yield. ${ }^{\mathrm{c}}$ Determined by gel permeation chromatography (GPC). ${ }^{\mathrm{d}} \mathrm{kg}$ polymer $(\mathrm{mol} \mathrm{V})^{-1} \mathrm{~h}^{-1}$. ${ }^{\mathrm{e}}$ Determined by ${ }^{1} \mathrm{H} \mathrm{NMR}$ and ${ }^{13} \mathrm{C} \mathrm{NMR} .{ }^{\mathrm{f}}$ [V3]/[Ip]/[MAO] = 1/2000/50. ${ }^{\mathrm{g}}$ [V3]/[Ip]/[MAO] = 1/2000/10.

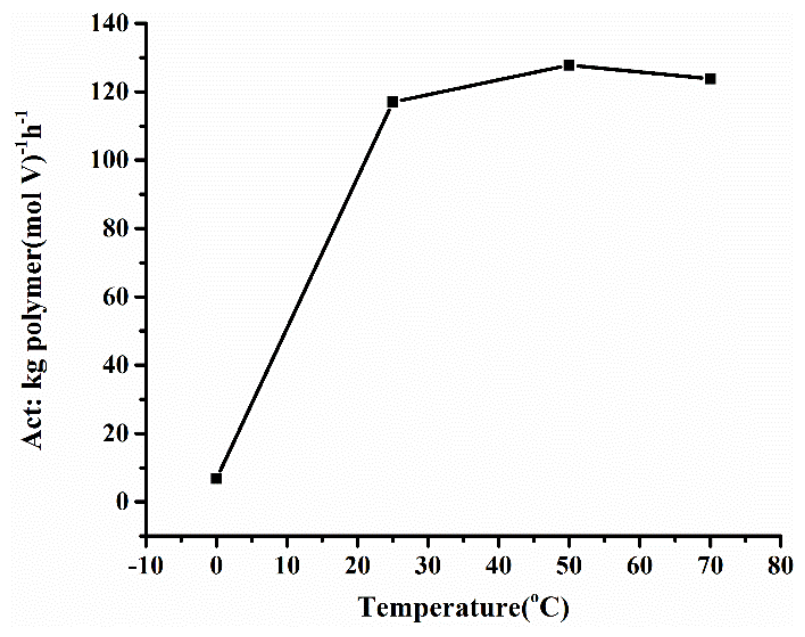

Figure 4. Catalytic activities of complex V3 with MAO at different temperature.

In comparison with previous works, the title iminopyridine-vanadium complexes displayed better catalytic performance in terms of activities and selectivities. For instance, Zink and coworkers studied isoprene polymerization using vanadium chelates of dianionic tetradentate amine-bisphenolate [ONNO]. These catalysts showed lower activities as required $8 \mathrm{~h}$ for complete conversions. The resulting polyisoprenes were composed of $70 \%$ of 3,4 units and $30 \%$ of the mixture of cis- 1,4 and trans-1,4 stereoisomers [41]. Similar results of low activities were found with vanadium catalysts bearing iminopyridine as ligand reported by Ricci in the patent, which only gave $80.7 \%$ conversion after $2 \mathrm{~h}$ [42]. Because vanadium catalysts reported herein could catalyze isoprene polymerization over $90 \%$ yield in $10 \mathrm{~min}$, and the resulting polyisoprene was mainly composed of cis-1,4 (75\%) units and 3,4 units(25\%).

\section{Conclusions}

In summary, a library of four vanadium complexes bearing iminopyridine ligands were synthesized, and their catalytic capacity for the polymerization of isoprene was investigated in detailed. The introduction of ligand to the vanadium center significantly improved the reactivity and selectivity of the catalyst as compared to the traditional $\mathrm{VCl}_{3} / \mathrm{MAO}$ system. Interestingly, the $\mathrm{N}$-phenyl substituted complex V3 was found to be the most effective catalyst $(75 \%$ of cis-1,4 and $25 \%$ of 3,4$)$ which allowed for high reactivity up to $734.4 \mathrm{~kg}$ polymer $(\mathrm{mol} \mathrm{V})^{-1} \mathrm{~h}^{-1}$ and excellent thermostability even at $70^{\circ} \mathrm{C}$. In conclusion, this study demonstrated a family of highly effective $\mathrm{V}$ (III) catalysts for isoprene polymerization. Further studies of iminopyridine vanadium complexes catalyzed the polymerization of other olefins are underway. 
Supplementary Materials: The following are available online at http://www.mdpi.com/2073-4360/11/7/1122/s1, Table S1: Effects of cocatalyst and solvent on the isoprene polymerization with $\mathrm{VCl}_{3}$ catalyst, NMR spectra of the representative polyisoprene and GPC curves of polyisoprene samples.

Author Contributions: Conceptualization, Q.W.; methodology, M.Z.; formal analysis, M.Z.; investigation, M.Z.; writing-original draft preparation, Q.M.; writing-review and editing, Q.W.; visualization, C.J.; funding acquisition, Q.W; assisted this work, L.W., G.Z. and X.Z.

Funding: This research was funded by Major Science and Technology Innovation Program of Shandong Province, grant number 2018CXGC1105 and CAS Hundred Talents Program, grant number Y5100719AL.

Acknowledgments: We gratefully acknowledge the generous support Young Taishan Scholars Program of Shandong Province (tsqn201812112) and "135" Projects Fund of CAS-QIBEBT Director Innovation Foundation.

Conflicts of Interest: The authors declare no conflict of interest.

\section{References}

1. Porri, L.; Giarrusso, A.; Ricci, G. Recent views on the mechanism of diolefin polymerization with transition metal initiator systems. Prog. Polym. Sci. 1991, 16, 405-441. [CrossRef]

2. Nishikawa, M.; Maeda, M.; Nakata, H.; Takamatsu, H.; Ishii, M. New isoprene polymers. Appl. Anionic Polym. Res. 1998, 696, 186-196.

3. Halasa, A.F.; Hsu, W.L. Synthesis of high vinyl elastomers via mixed organolithium and sodium alkoxide in the presence of polar modifier. Polymer 2002, 43, 7111-7118. [CrossRef]

4. Hou, Z.M.; Wakatsuki, Y. Recent developments in organolanthanide polymerization catalysts. Coord. Chem. Rev. 2002, 231, 1-22. [CrossRef]

5. Ouardad, S.; Bakleh, M.-E.; Kostjuk, S.V.; Ganachaud, F.; Puskas, J.E.; Deffieux, A.; Peruch, F. Bio-inspired cationic polymerization of isoprene and analogues: State-of-the-art. Polym. Int. 2012, 61, 149-156. [CrossRef]

6. Horne, S.E.; Kiehl, J.P.; Shipman, J.J.; Folt, V.L.; Gibbs, C.F.; Willson, E.A.; Newton, E.B.; Reinhart, M.A. Ameripol SN-A cis-1,4-polyisoprene. Ind. Eng. Chem. 1956, 48, 784-791. [CrossRef]

7. Cooper, W.; Vaughan, G. Crystallization of gutta percha and synthetic trans-1,4-polyisoprenes. Polymer 1963, 4, 329-340. [CrossRef]

8. Ricci, G.; Leone, G.; Boglia, A.; Bertini, F.; Boccia, A.C.; Zetta, L. Synthesis and characterization of isotactic 1,2-poly (E-3-methyl-1,3-pentadiene). Some remarks about the influence of monomer structure on polymerization stereoselectivity. Macromolecules 2009, 42, 3048-3056. [CrossRef]

9. Ricci, G.; Leone, G.; Boglia, A.; Boccia, A.C.; Zetta, L. cis-1,4-alt-3,4 Polyisoprene: Synthesis and characterization. Macromolecules 2009, 42, 9263-9267. [CrossRef]

10. Ricci, G.; Sommazzi, A.; Masi, F.; Ricci, M.; Boglia, A.; Leone, G. Well-defined transition metal complexes with phosphorus and nitrogen ligands for 1,3-dienes polymerization. Coord. Chem. Rev. 2010, 254, 661-676. [CrossRef]

11. Ricci, G.; Boffa, G.; Porri, L. Polymerization of 1,3-dialkenes with neodymium catalysts. Some remarks on the influence of the solvent. Makromol. Chem. Rapid Commun. 1986, 7, 355-359. [CrossRef]

12. Oehme, A.; Gebauer, U.; Gehrke, K.; Beyer, P.; Hartmann, B.; Lechner, M.D. The influence of the catalyst preparation on the homo- and copolymerization of butadiene and isoprene. Macromol. Chem. Phys. 1994, 195, 3773-3781. [CrossRef]

13. Fischbach, A.; Meermann, C.; Eickerling, G.; Scherer, W.; Anwander, R. Discrete lanthanide aryl (alk) oxide trimethylaluminum adducts as isoprene polymerization catalysts. Macromolecules 2006, 39, 6811-6816. [CrossRef]

14. Zimmermann, M.; Törnroos, K.W.; Anwander, R. Cationic rare-earth-metal half-sandwich complexes for the living trans-1,4-isoprene polymerization. Angew. Chem. Int. Ed. 2008, 47, 775-778. [CrossRef] [PubMed]

15. Liu, B.; Cui, D.M. Regioselective chain shuttling polymerization of isoprene: An approach to access new materials from single monomer. Macromolecules 2016, 49, 6226-6231. [CrossRef]

16. Ricci, G.; Battistella, M.; Porri, L. Chemoselectivity and stereospecificity of chromium (II) catalysts for 1,3-diene polymerization. Macromolecules 2001, 34, 5766-5769. [CrossRef]

17. Bazzini, C.; Giarrusso, A.; Porri, L. Diethylbis (2,2'-bipyridine)iron/MAO. A very active and stereospecific catalyst for 1,3-diene polymerization. Macromol. Rapid Commun. 2002, 23, 922-927. [CrossRef] 
18. Pirozzi, B.; Napolitano, R.; Petraccone, V.; Esposito, S. Determination of the crystal structure of syndiotactic 3,4-poly (2-methyl-1,3-butadiene) by molecular mechanics and X-Ray diffraction. Macromol. Chem. Phys. 2004, 205, 1343-1350. [CrossRef]

19. Raynaud, J.; Wu, J.Y.; Ritter, T. Iron-catalyzed polymerization of isoprene and other 1,3-dienes. Angew. Chem. Int. Ed. 2012, 51, 11805-11808.

20. Guo, L.H.; Jing, X.Y.; Xiong, S.Y.; Liu, W.J.; Liu, Y.L.; Liu, Z.; Chen, C.L. Influences of alkyl and aryl substituents on iminopyridine Fe(II)- and Co(II)-catalyzed isoprene polymerization. Polymers 2016, 8, 389. [CrossRef]

21. Zhu, G.Q.; Zhang, X.H.; Zhao, M.M.; Wang, L.; Jing, C.Y.; Wang, P.; Wang, X.W.; Wang, Q.G. Influences of fluorine substituents on iminopyridine Fe(II)- and Co(II)-catalyzed isoprene polymerization. Polymers 2018, 10, 934. [CrossRef] [PubMed]

22. Zhang, X.H.; Zhu, G.Q.; Mahmood, Q.; Zhao, M.M.; Wang, L.; Jing, C.Y.; Wang, X.W.; Wang, Q.G. Iminoimidazole-based $\mathrm{Co}(\mathrm{II})$ and $\mathrm{Fe}(\mathrm{II})$ complexes: Syntheses, characterization, and catalytic behaviors for isoprene polymerization. J. Polym. Sci. Part A Polym. Chem. 2019, 57, 767-775. [CrossRef]

23. Zhao, M.M.; Wang, L.; Mahmood, Q.; Jing, C.Y.; Zhu, G.Q.; Zhang, X.H.; Wang, X.W.; Wang, Q.G. Controlled isoprene polymerization mediated by iminopyridine-iron (II) acetylacetonate pre-catalysts. Appl. Organomet. Chem. 2019, 33, e4836. [CrossRef]

24. Natta, G.; Pino, P.; Corradini, P.; Danusso, F.; Mantica, E.; Mazzanti, G.; Moraglio, G. Crystalline high polymers of $\alpha$-olefines. J. Am. Chem. Soc. 1955, 77, 1708-1710. [CrossRef]

25. Gambarotta, S. Vanadium-based Ziegler-Natta: Challenges, promises, problems. Coord. Chem. Rev. 2003, 237, 229-243. [CrossRef]

26. Redshaw, C. Vanadium procatalysts bearing chelating aryloxides: Structure-activity trends in ethylene polymerisation. Dalton Trans. 2010, 39, 5595-5604. [CrossRef]

27. Nomura, K.; Zhang, S. Design of vanadium complex catalysts for precise olefin polymerization. Chem. Rev. 2011, 111, 2342-2362. [CrossRef]

28. Wu, J.-Q.; Li, Y.-S. Well-defined vanadium complexes as the catalysts for olefin polymerization. Coord. Chem. Rev. 2011, 255, 2303-2314. [CrossRef]

29. Lovering, E.G.; Wright, W.B. Evidence for several species of active sites in Ziegler-Natta catalysts. J. Polym. Sci. Part A Polym. Chem. 1968, 6, 2221-2235. [CrossRef]

30. Ricci, G.; Panagia, A.; Porri, L. Polymerization of 1,3-dienes with catalysts based on mono- and bis-cyclopentadienyl derivatives of vanadium. Polymer 1996, 37, 363-365. [CrossRef]

31. Sigaeva, N.N.; Saitova, F.F.; Mullagaliev, I.R.; Glukhov, E.A.; Maksyutova, E.R.; Monakov, Y.B. Polymerization of isoprene with vanadium-containing catalysts: Kinetic nonuniformity of active centers. Polym. Sci. Ser. A 2006, 48, 257-265. [CrossRef]

32. Monakov, Y.B.; Mullagaliev, I.R.; Kharitonova, E.Y. Butadiene polymerization in the presence of $\mathrm{VOCl}_{3}$-Dialkylmagnesium catalytic system. J. Appl. Polym. Sci. 2003, 89, 596-600. [CrossRef]

33. Cao, L.H.; Dong, W.M.; Jiang, L.S.; Zhang, X.Q. Polymerization of 1,3-butadiene with $\mathrm{VO}\left(\mathrm{P}_{204}\right)_{2}$ and $\mathrm{VO}\left(\mathrm{P}_{507}\right)_{2}$ activated by alkylaluminum. Polymer 2007, 48, 2475-2480. [CrossRef]

34. Giovanni, R.; Lucia, Z.; Enrica, A.; Tiziano, M.; Maurizio, C.; Fabio, B. Butadiene-isoprene copolymerization with V(acac) ${ }_{3}-\mathrm{MAO}$. Crystalline and amorphous trans-1,4 copolymers. J. Polym. Sci. Part A Polym. Chem. 2007, 45, 4635-4646.

35. Wang, H.Y.; Cao, L.H.; Zhang, X.Q. Polymerization of 1,3-butadiene with $\mathrm{VO}\left(\mathrm{P}_{204}\right)_{2}$ activated by methylaluminoxane, purified methylaluminoxane, and trimethylaluminum. J. Appl. Polym. Sci. 2013, 127, 4594-4600. [CrossRef]

36. Natta, G.; Zambelli, A.; Lanzi, G.; Pasquon, I.; Mognaschi, E.R.; Segre, A.L.; Centola, P. Polymerization of propylene to syndiotactic polymer. Part. I: Valence of active vanadium in the catalytic systems. Die Makromol. Chem. 1965, 81, 161-172. [CrossRef]

37. Hagen, H.; Boersma, J.; van Koten, G. Homogeneous vanadium-based catalysts for the Ziegler-Natta polymerization of $\alpha$-olefins. Chem. Soc. Rev. 2002, 31, 357-364. [CrossRef]

38. Colamarco, E.; Milione, S.; Cuomo, C.; Grassi, A. Homo- and copolymerization of butadiene catalyzed by an bis(imino)pyridyl vanadium complex. Macromol. Rapid Commun. 2004, 25, 450-454. [CrossRef]

39. Chang, H.C.; Son, B.C.; Song, G.Y.; Shin, J.Y.; Ha, C.-S.; Suh, H.; Kim, I. (E)-N-((1H-benzo[d]imidazol-2-yl)(phenyl)-methylene)quinolin-8-amino cobalt(II), iron(II), nickel(II), 
chromium(III), and vanadium (III) complexes and their activities towards ethylene and 1,3-butadiene. Macromol. Res. 2013, 21, 118-121. [CrossRef]

40. Leone, G.; Zanchin, G.; Pierro, I.; Sommazzi, A.; Forni, A.; Ricci, G. Synthesis, structure and 1,3-butadiene polymerization behavior of vanadium(III) phosphine complexes. Catalysts 2017, 7, 369. [CrossRef]

41. Phuphuak, Y.; Bonnet, F.; Vendier, L.; Lorber, C.; Zinck, P. Isoprene polymerization mediated by vanadium-[ONNO] complexes. Dalton Trans. 2016, 45, 12069-12077. [CrossRef] [PubMed]

42. Ricci, G.; Leone, G.; Sommazzi, A.; Masi, F. Vanadium Pyridine-Imine Complex, Catalytic System Comprising Said Vanadium Pyridine-Imine Complex and A (Co)Polymerization Process of Conjugated Dienes. U.S. Patent Application No 15/765782, 2017.

43. Zhang, S.-W.; Lu, L.-P.; Long, Y.-Y.; Li, Y.-S. Ethylene polymerization and ethylene/hexene copolymerization by vanadium(III) complexes bearing bidentate phenoxy-phosphine oxide ligands. J. Polym. Sci. Part A Polym. Chem. 2013, 51, 5298-5306. [CrossRef]

(C) 2019 by the authors. Licensee MDPI, Basel, Switzerland. This article is an open access article distributed under the terms and conditions of the Creative Commons Attribution (CC BY) license (http://creativecommons.org/licenses/by/4.0/). 